\title{
Interview
}

\section{An interview with Cheryl McKinnon, Chief Marketing Officer of Nuxeo}

\begin{abstract}
Cheryl McKinnon
is Chief Marketing Officer, With more than 16 years experience in Enterprise Content Management, Mc Kinnon has developed a keen interest in the challenges facing information workers in the increasingly electronic and online work environment. Her specialty is researching, articulating and educating on current and emerging trends in information management. Holding progressively senior positions with key vendors such as Nuxeo, and formerly Open Text, Hummingbird and PC DOCS, she brings years of market and requirements research in addition to experience in consulting and training. An active member of industry associations such as AIIM and ARMA, she frequently contributes articles and opinions to online and print publications, and speaks regularly at industry conferences. She holds a BA (Hons.) from the University of Winnipeg, a Master of Arts from Carleton University, and has completed the required coursework towards a $\mathrm{PhD}$ in History at the University of Ottawa (though regrettably she remains 'ABD').
\end{abstract}

\begin{abstract}
Nuxeo announced the availability of Nuxeo DAM, its first digital asset management application earlier this year. An established vendor offering open source Enterprise Content Management since 2000 , this move into DAM was largely prompted by demand from its diverse install base. Nuxeo DAM builds on the strength of the Nuxeo Enterprise Platform, a highly extensible Java-based environment designed specifically for content applications. Nuxeo DAM has been designed with the creative content consumer in mind - offering the key functionality needed to manage multiple renditions of rich content, ease the storage burden, protect against intellectual property or copyright breaches, and enable easy and intuitive search and navigation through media assets. This article provides insights into Nuxeo's market strategy, differentiation and why DAM is an essential move for the company.
\end{abstract}

Journal of Digital Asset Management (2010) 6, 159-165. doi:10.1057/dam.2010.12

Keywords: open source; content management; interoperability; standards; Java; platforms

MM: Okay, we are here with Cheryl Mckinnon. Cheryl would you give us a bit of your background both in terms of your current position and a short summary of your career. Cheryl: Yes, my name is Cheryl McKinnon and my current role is that of Chief Marketing Officer with Nuxeo. Nuxeo is an open source enterprise content management company that just recently announced a digital asset management release. I joined Nuxeo in September 2009 having spent the last 15 years working with some of the larger content management vendors in the market, such as Open Text, Hummingbird, PCDOC and some System Integrators. I spent most of my working career in the world of electronic and digital content management with several roles in marketing and market research, as well as solutions and product management, and technical training and consulting before that. My academic background is actually more in the area of archives and history, so I have a strong interest in all aspects of digital longterm preservation, making sure that we are taking care of the digital artifacts in both our professional and personal lives.

MM: Excellent and could you give us an overview of Nuxeo on both its name and a little bit of its story and history.

Cheryl: Sure, the company was actually founded in the year 2000, so while we are a new name in North America, it is actually 
quite a well-established technology company in Western Europe; specifically in France, with its global headquarters in Paris. Many of the senior management team comes right from that very early founding period. So, I work very closely with the whole management team including Eric Barroca, the CEO and Stefane Fermigier, who is one of the original founders and current chair of the board. In terms of the company evolution, we are just over 50 people globally right now; primarily in the Paris headquarters. We have expanded from one person to seven just in the last year in the North American office, which is based in Burlington, Massachusetts. North America has been a very big area for expansion for us over the last 12 months. The company has been focused for the first 5 years on building a content management framework and platform and the related services to deploy and support them. With a company change in focus, a little bit around the 2005 time frame, we went through a technology re-architecture and developed a base content management framework on the Java environment. Since then, we have worked to develop a very strong open source and open standards-friendly Enterprise Content Management (ECM) framework along with the packaged applications that end-user organizations can take, test and deploy for their own specific needs. The digital asset management product was officially launched in February 2010, although it went into public beta in December 2009, and has very quickly found a wide base of interest both in Europe and North America.

MM: And in terms of the current base of customers, about how many customers does Nuxeo have worldwide and in North America. Cheryl: Well, it is interesting because in the world of open source, we can easily say that we have thousands of deployments; the way in which we count this as a customer per se is those who have engaged with us for a formal support and maintenance contract. So, over the course of the company history, we have had hundreds of those. Right now, we have approximately 150-200 active support contracts at any given time. We are seeing very nice year-over-year growth, and, specifically, we are seeing very good traction coming out of the North American market.
MM: Do you have a specific number with respect to North America?

Cheryl: Within North America, I would say we are easily between 12 and 15 new full-time supported customers since 2009.

MM: And do these customers, either North America or Europe, fall in a particular account or particular industry segment or vertical market?

Cheryl: We do have several: I think we probably have five markets where we tend to see very specific successes, although we do have customers certainly in nearly all of the major categories. If we were to talk about the top few vertical segments, I would say that in no particular order it is the government, meaning all levels of public sector including military and the intelligence sector, with a very strong install base in Western Europe and increasingly in North America, especially at the state and local level. In fact, it was some of our military customers who really gave us the inspiration to move into the area of digital asset management out of our core ECM framework. Secondary level of industry, again, has a lot of strength in the education market. Open source typically is very appealing to education because you can get started at a fairly low cost of ownership, so we do well with $\mathrm{K}-12$ as well as university and academic research institutes that are quite high on that list. Also, we have strong traction in the entire area of transportation and aeronautics, again, both in US and Europe. We have a platform that scales in a very interesting way. We can support very large deployments and a large number of users and content types; but because of the nature of our architecture, we can also scale down those that are fairly small, very lean and skinny, meaning that we can run on hardware and operating system environments that many of our mainstream competitors cannot. So, in verticals such as military, aerospace and transportation, we can typically run in some very creative types and environments where we do not assume it is going to be very high-capacity, high-powered server infrastructures. We are also seeing a lot of new businesses coming out of construction and the related professions and that whole value chain around architecture engineering and in life sciences, including biotech and pharmaceuticals. 
MM: Well, it certainly covers the gamut. Would you please speak to the market context of open source as a way of setting up two or threes threads that we might develop? Cheryl: So I think you know what I find rather interesting because, again, I spent 15 years of my career in the more traditional proprietary software world. Where I found the open source approach to development and distribution of software particularly interesting is that, the company can be extremely responsive to the demands of the customer community. So, specifically, around a lot of the motivation coming from our movement into the area of digital asset management, as I mentioned, came from several of our existing customers who have increased demand for the storage and handling of rich media such as video, audio, and rich graphic and image formats. Because we operate in an open source model, it means customers or partners or even just interested community participants can review, contribute to and update our source code, assuming that it goes through a proper QA process of course, but it means that we can innovate very quickly and be responsive to where our customer market is going. So, that is certainly one advantage. Where open source is also a little different is that we allow our prospects who are just investigating their digital asset management requirements to actually go and download the packaged application right from our web site. So, they can actually go download the production version of our code, implement it, begin the prototyping, look at their requirements and make an informed decision as to whether our product meets their needs or not. We then let them kind of get that whole investigative cycle moving very quickly, essentially in a matter of hours, and we do not move into that whole hula hoop jumping cycle of negotiating, evaluating, licensing or having to set them up with test environments, etc. We try to make it as easy as possible for interested, motivated customers to get their hands on the product as quickly as possible.

MM: That is what; I wanted you to develop a little more fully in that open source software at least, as many people understand, including me, that it tends to require an ecosystem of third and fourth parties really to kind of build out things, utilities, scripts, applications and hooks into other systems. The second thing is that it tends to speak to a company or business requirements that are cost constrained; that is, it is the general perception that it is cheaper for the technical framework to look for something that is much more moldable or shapeable for our business requirements.

Cheryl: Yes, that is absolutely right. So, we do tend to appeal more to an organization that does have a technical team internally who can evaluate it, make a decision and be interested in updating it or doing customizations that need very specific business requirements. We do not necessarily require a lot of third-party scripting and tool building, but we do actively encourage that healthy kind of partner community around us because it just continues to make our product more easily consumed and integrated into more and more mainstream, other line of business applications such as Enterprise Resource Planning (ERP) systems. We do actually encourage a lot of that third-party enhancement and innovation on our core platform, but the majority of the development work is in fact done by our own core team in order to try to find that right balance between having that strength of the technology platform that is going to appeal to companies that you know internally, but we also do invest time in trying to wrap up a very compelling simple user interface, so that we can be used essentially out of-the box too. What is really important for Nuxeo and our development team is to find that right balance of keeping it wide open for the really heavy-duty developers who get the strength of the platform, but at the same time making it a simple non-alienating, a compelling friendly user experience for someone who is perhaps a campaign manager in a marketing group or someone who is managing video for a company's e-learning application - these are really the use cases we see the product evolving into.

MM: DAM, as broadly defined, entails or may include many things and, conventionally or in the most basic sense, often refers to technology or a system for managing the certain retrieval of non-descriptive files, photographs, videos, etc. and, to that end, they generally support one of three or so basic activities or processes; one is basically just a library of controlled objects, 
could be an image or a marketing library application of the DAM that folds more on the creative workflow or the content creation workflows, and there DAM really serves more of an orchestration function in terms of managing an approval process and working process and all of the bits that go into composite medial expressions and then the third aspect of DAM in other sorts of things really relate to how a company creates and builds engaging content via print, online broadcast or whatever, and their DAM has really been expanded to include not just non-descriptive assets such as images or videos, but textual information in the form of product claims, marketing communications and other copies of written material. Could you speak to how NUXEO supports or fits into any of those three or all of those three?

Cheryl: Yes, I would say that of those three, in the early release v. 1.0 that we are looking at today, we certainly support use cases 1 and 3 quite well. I would also say that for use case number 2 , in terms of really being part of that active creative creation process, this is something that we are looking at now for the future. We now have our early adopters on board, and they are really telling us which of the creative tools are highest priorities in terms of our next-integration road map. So, in terms of the first use case, we really do see that more and more organizations are investing or curating or collecting content in a very wide range of form created for both formal business purposes and marketing purposes that include a whole range of user-generated content, which is perhaps of lower quality, but that is still very interesting content that they may want to use either internally or externally. So, we have work to make sure that we are very strong on the repository side with the ability to search, the ability to apply any form of either out-of-the-box metadata, including things like standards for Dublin Core for many of the specific photographic standards such as IPTC and EXIF. Certainly it is all there out of the box and the ability to automate the batchup load, and extraction of a lot of that metadata for images coming off of a sim card or out of zip file or from other source. Because we are built on an underlying content repository that already has many proven deployments, it means that we do have a lot of that search capability, that organizational capability, the ability to you know create folders based on customer projects or divisional names and address any kind of organizational scheme that really matters to the company. The user experience that we developed specifically for DAM is visibly compelling, so very much a thumbnail view instead of a folder view, which you may expect in a more traditional document management environment. We wanted to make it very bright and visually appealing for people to know quickly that yes, that is the right photo and that is the right image I want to use in my documents. We are also able to manage all the various iterations or renditions of an image, so if I have three to four renditions in the same picture, perhaps some intended for you know glossy print versus publish to the web versus more appropriate for thumbnail previews, we were able to manage all of those iterations or renditions under a single set of metadata. So we know which is which, we tried to make sure that we got unique URLs for each of those particular renditions, making it very simple for someone to know that they got the right piece of the information for the right kind of context. On the third use case, more around kind of a comprehensive digital environment, we are actually seeing requests for some of those early adopters who are coming from fairly regulated industries in the financial sector as well as life sciences. In addition to wanting to manage the right logos and images for perhaps an ad campaign, they absolutely do want to have all of those designs for packaging, so may be they have five different packaging for the pill bottle, for example because jurisdictions have different rules around disclosure or warning labels, all sorts of things. Even that compelling rich content is often subject to much of the compliance pressures for regulated, consumer goods for example. So, we absolutely do have a very strong connection between the digital asset management offering that we have and the underlying document manager repository, which really both share the same base content foundation. MM: So going back to the framework as an open source offering could you take us through the typical deployment process, as it specifically relates to not just DAM but DAM in a workflow? 
Cheryl: I do not think the process is much different than a typical proprietary offering, but perhaps the time scale at particular phases of the project are done a little different. So, typically, an organization will find us either because they searched online and found us or because they have met us through a trade publication or trade event or they already know us from some of our other more traditional document management products and they want to know about our new offers. When they decide that they want to investigate our offerings, then again because we are open source, they can simply go download the packaged offering and get to work in terms of prototyping or deepening their hands on requirements analysis. We do find that it is typically after a couple of days or few weeks of that self-learning or self-assessment that the company will then contact us with either further questions or because they want a deeper understanding of our road map or integration plans. At that point, if they think that the product is meeting their requirements, they will start investigating questions around what we offer in terms of support, pricing, maintenance, training, consulting, etc. The first few deals that we have had typically have gotten to that stage of a pricing proposal and initial purchase of their maintenance contract, within about 2 months, so it is typically a bit of a faster sales cycle, than some of the larger more established DAM vendors in the market.

MM: It does not, is not that more I will call it open source marketing approach of first putting the code into hands of a prospective customeralbeit a more technically inclined customer - so that they can at least validate the underlying framework and the general applicability. Does this not then put a greater emphasis on a more structured service fulfillment or professional services framework than you would normally have with a packaged software.

Cheryl: I think that it is actually a very good point and where we derive the bulk of our revenue stream is actually around the sale of our annual support and maintenance contracts. We offer a series of support subscription services, we call it Nuxeo Connect and that is what gives the customer a very structured approach to issue resolution, you know logging a bug, getting that certified patch turn around and $X$ number of hours depending on their service level agreement. So, we have an entry-level package for someone who is perhaps budget constrained or runs a small business; but then, if it is a large production environment with $24 \times 7$ critical applications, we certainly have tiers of response times to ensure that very quick business day turn around time. That is where we make the bulk of our revenue through support maintenance, tested patches, tested upgrade policy etc. We also have a traditional professional services offering, so we do have for example, templated kind of packaged services, engagements, getting-started types of project plans where we would go and do that initial workshop to verify requirements, come back with that specification; at that point, we map out if there is any kind of customization work, what is the scope of that beyond that initial subscription service. We are then able to do a short consulting engagement to verify the final requirements and determine how much of the consulting and implementation the customer is able to do, do they perhaps want one on their service providers or assistance integrators to do some work and how much do they want to contract us as a vendor.

MM: Once I would like to kind of shift our focus to how customers would compare and contrast Nuxeo offering with other open source DAM offerings such as more classic enterprise DAM applications say from North Plains or Open Text.

Cheryl: We are beginning to hear customers provide feedback on our comparison to some of the other open source platforms. I would not say that I have hands-on experience with all of them, but we have had customers comment a little bit about our services, for example. There may be a perception that perhaps we do not have all of the building objects just yet. But where we have actually competed successfully in one case against the other open source more established DAM that there is, it is the overall breadth of the whole content management platform that we bring to the table. So, we see DAM as a natural extension to or a natural adjacent area to an overall corporate electronic content strategy. We not only offer all of the most important digital asset management capabilities in terms of the rich media support, the IP management, all of the extended 
metadata, search, filtering, etc., but also all of the underlying platform strength that we have because of our many years in the document management world - this also trickles up into our platform. So, that means that we are already based on a strong Java workflow engine that allows organizations to push very structured or rigid approval cycles that are able to set various document phases or stages to life-cycle management. We are building on the strength of many years of development expertise already. We have a road map for the overall platform to move more into a lot of the information and governance or records management requirements coming out of the US Federal DOD 5015.2 Records Management standard, which means that will naturally trickle into our digital asset management offerings. So, if an organization was hit with a law suit and had to do e-discovery on their assets, perhaps it was the wrong packaging label that was shipped to a particular country for a new drug for example, everything in our repository would be able to benefit from the enhancements we placed towards that. In addition, if there is information, perhaps after a project is completed or there is a trigger to destroy or delete that content, because it is in a platform that already meets all those requirements, we will be able to satisfy that.

MM: So, how would you then compare and contrast the NUXEO offering to your competitors? Cheryl: Okay, so I'll address this in terms of looking at our strengths compared to something like the Media Bin, which was from Interwoven/Autonomy or formerly Artesia DAM, which is now part of Open Text. When we look at some of those bigger, more established vendors, a couple of things: no. 1 is we tend to appeal certainly from an upfront financial investment perspective. So, while certainly, we will engage with those customers for the long-term support and maintenance contracts as with the proprietary vendors, we dispense with that upfront license negotiation or that upfront license investment to get the projects moving much more quickly, so from a financial investment perspective that is one advantage to our business model. The second is that because our underlying core was architected using a very innovative Java architecture in 2005, we are built with a much leaner, more modular, more granular services metaphor behind the scene, which means that organizations do not need to invest in the entire offering if they only need a partial feature set. So, if you are running in an environment, perhaps, that is very mobile or fragmented or decentralized, and perhaps you need to serve up architectural drawings to construction sites and it is on an unreliable or temporary network environment, we are ideal because we can run very lean on a variety of hardware and operating system environment. We tend to fit nicely into environments that do not have the big multi-CPU server infrastructures that, perhaps, some of the bigger, more established players would require. Also, because we were built with a very open architecture in mind, we are very not only committed to open source, but also open standards. It means that we can very easily keep up with emerging trends and standards such as CMIS, a recently approved content management interoperability standard from OASIS which is emerging primarily as a document management-driven interoperability standard, but again because we have an underlying common platform, which means that our digital asset management offering can also very rapidly take advantage of those open interoperability standards. This means that we can plug on almost immediately behind other web content management systems that are also adopting those standards.

MM: As I understand you right, the offering that you bring to the market has strong roots and records management as well as document or content management and of course now digital asset management.

Cheryl: That is right, so where we do have that common underlying platform, we have developed the DAM offering as an offshoot of it, with a metadata model that is specific to DAM, and with an extended feature set as well as a new user interface that is very picture and image friendly.

MM: Right. Excellent. Well, as we begin to move to the end of our interview here, is there anyway you can perhaps start to summarize things in terms of how you see the customer requirements and/or market evolving over the next, say, 3 or 5 years?

Cheryl: Sure and this is where, working with some of our early-adopted customers, they 
have already been talking about some of these fascinating and fairly new use cases for digital asset management. One of our customers in the financial services field actually wants to take a look at publishing - or restricting from publishing for example - some of their videos or image content to social media sites, such as Facebook. So, that whole area around control, over where the content is copied and is pushed with what kind of IP rights or what copyright information goes along with the content, those are some of the new areas that are starting to emerge for us and are very fascinating. So, the ability to integrate to other content sources for either downloading or pushing the content for consumers, being able to address the consumer audience is quite fascinating, because I think the advent of this world of social media has really changed where companies want to be able to expose their rich media content. You cannot assume anymore that someone is going to come to your web site to experience your offering or learn about your new service, you know banking service, etc., but for most industries, you may need to go to where your consumers are and that may be a social site, such as a community group or Facebook, or other types of business communities that may be linked in here a B to B type of offering. So, that is certainly a changed game in terms of where you push and pull that content from, perhaps your corporate repository. I think the second is just desire of rich content for more and more corporate communication where now perhaps training content in a video is not necessarily in a printed document where I need traditional text document, which mean a lot more of the interactive media needs to be subject to the same kind of governance rules as you would expect with word processing or PDF documents. Some of the governance requirements, perhaps coming out of the document and records management are explicitly - or at least implicitly behind the scenes - carrying over to the digital asset management. This is increasingly becoming important as more and more jurisdictions worldwide start adopting laws around electronic discovery. Certainly, the US led the way in 2006 around the Federal Rules of Civil Procedure changes where essentially any electronic content is now fair game for legal discovery. So, I may have to essentially disclose my video, my pod cast, my taped phone conversation to opposing legal counsel. The jurisdiction of Ontario in Canada just adopted the very same kind of law just in January 2010. So, anything that is electronically stored now is becoming subject to some of this and that really raises many questions. What about all of these videos, images and sound files? Should we treat this as supporting information or is it a little bit more light weight? Is it as corporately sensitive, perhaps, as a printed wordprocessing or spreadsheet file? I think the mindset is going to change very quickly as the laws begin to change.

MM: This is a great place to conclude.

Cheryl: Okay.

MM: We want to thank you very much and I look forward to perhaps seeing you in person at one of the conferences.

Cheryl: Wonderful, well thank you so much for taking the time for us, we do appreciate it. 